\title{
Mobile Phone Usage and Its Effects on Pedestrians' Distraction
}

\author{
Naser Alejalil, ${ }^{1}$ and Seyed Rasoul Davoodi ${ }^{2, *}$ \\ ${ }^{1}$ Department of Civil Engineering, Ahar Branch, Islamic Azad University, Ahar, IR Iran \\ ${ }^{2}$ Department of Civil Engineering, Faculty of Engineering, Golestan University, Gorgan, IR Iran \\ "Corresponding author: Seyed Rasoul Davoodi, Department of Civil Engineering, Faculty of Engineering, Golestan University, Gorgan, IR Iran. E-mail: davoodi76ir@gmail.com
}

Received 2015 December 17; Revised 2016 April 04; Accepted 2016 November 05.

\begin{abstract}
Background: The use of mobile phones in the world today is growing rapidly and consequently its related problems in various areas of cultural, social and economical are growing.

Objectives: The current research was concerned with aspects of mobile phone use and pedestrian distraction when talking on a mobile device.

Patients and Methods: The present survey took place on a university campus. Five objects were placed along the route. Volunteers participating in the study were divided into two groups. The experimental group received phone calls their entire path, while the control group did not receive any phone calls. At the end of the survey, the participants were asked which of these objects were seen along the path.

Results: The results revealed that $20 \%$ of the answers were correct for the participants in the call condition group, while $74 \%$ of the answers were correct for the participants in the no call condition group. Results indicate that there are significant differences between the two groups from the response aspect.

Conclusions: The findings of the present study suggest that cell phone usage while walking can decrease the perceptual visual field, make pedestrians less aware of the surroundings and put them at the risk of having an accident, getting injured or death. It is necessary to give pedestrians adequate training in the field of mobile device usage and its possible risks as well as teach them its appropriate use. They should also be taught to put their cell phones away while walking in the street especially when they are crossing a street or at the intersections.
\end{abstract}

Keywords: Distraction, Mobile Phone, Pedestrian

\section{Background}

The use of mobile phones in the world today is growing rapidly and consequently its related problems in various areas of cultural, social and economical are growing. Regarding the fact that $77 \%$ world population owns a cellphone, it was estimated that 6.1 trillion messages were sent worldwide in 2010, which is tantamount to 200,000 messages every second (1). The percentage of Iranians who use a cellphone to access the Internet, email, or instant messaging has increased. According to the union, the mobile phone penetration rate of $84 \%$ has been declared in Iran, which shows a significant rise in recent years (2).

WHO reports that it is astonishing that the pedestrians make $22 \%$ of all traffic fatalities of the world's roads annually, where more than 270,000 lose their lives. Moreover, it is substantiated that this percentage accounts for two thirds of all traffic deaths in some countries (3). However, in Iran more than 70,000 pedestrians were injured and more than 4,000 lost their lives illustrating that $22 \%$ of all road traffic fatalities and nearly $55 \%$ of them were in urban areas (4).

Although counter measures such as street and inter- section designs or dangerous driving can be responsible for pedestrians' injuries, studies show that reckless behavior causes $15 \%$ of pedestrians' accidents (5). It is reported that pedestrians are distracted by many interferences such as smoking and listening to music, but the most common distractor is the inappropriate use of a cellphone (5-7). There is a rapid increase in the number of pedestrians who use cell phones for talking or text messaging while crossing the street (8-11). It seems that cellphones have become increasingly advanced, allowing pedestrians to do much more than just making a phone call or sending a text message.

Given the complexity of accurately judging the safety of a street crossing, along with the necessity of devoting careful attention to key stimuli, the task of crossing a street likely becomes even more challenging when pedestrians become distracted by attempting to use a cellphone (12). If attention is directed elsewhere, the cognitive processing needed to make a safe street-crossing decision may become disrupted and may be less effective (13).

Distracted pedestrians cause many pedestrian injuries. Strayer and his colleague's (14) conducted a survey in the United States on 699 people who had been involved in an 
accident with a vehicle. The results indicated that $25 \%$ of them were talking on their cellphones 10 minutes before the accident. Two possible sources of distraction for cellphone use are documented. The first kind of distraction refers to the physical aspect of holding the phone and dialing (15-17) and the second one pertains the person's attentive resources to the conversation on the cellphone (18-21).

Since crossing the street requires considerable cognition and attention, pedestrians using a cellphone are less likely to look at traffic before crossing, to wait for traffic to stop, to look at traffic while crossing or to walk briskly (6). Hyman et al.'s (22) findings proved that using cellphones while driving could cause some problems, for example, pedestrians using cellphones took a longer time to get to their destination, changed directions frequently and were less aware of their unusual surroundings at considerably higher levels than those pedestrians who were not on their cellphones. They also concluded that pedestrians talking on cellphones in a simulated environment took longer to cross the street and paid less attention to traffic; to put it precisely, pedestrians had more missed opportunities crossing against traffic and more simulated hits or close calls than those pedestrians with no cellphone distraction $(13,23)$. Thompson and her colleagues (9) indicated that nearly one-third of pedestrians (29.8\%) were distracted by their mobile devices while crossing the street.

Schwebel et.al in 2012 conducted a research to determine the effectiveness of activities such as listening to music, talking on their mobile device and sending and receiving messages by mobile phone on the distraction of pedestrians on 138 students from University of Alabama in a semi-virtual pedestrian crossing environment. Results clearly showed that doing these activities considerably reduces the consciousness of passers by doing these activities and the probability of collisions with motor vehicles increases. The study also revealed that the probability of pedestrian accidents is more in those who are distracted with writing the text or listening to music than those who are distracted by conversation (13).

Hatfield and Murphy (6) conducted an observational study on 270 women and 276 men who were crossing the street and found that amongst both of them, time of crossing the road increased when using the phone, and therefore, the likelihood of crash of motor vehicles would increase. Alternatively, Nasar and Troyer (24) conducted a study on pedestrians' injury that used mobile phones in public places; they used a national electronic injury surveillance system (NEISS) to find the number of injuries caused by cellphone use amongst drivers and pedestrians (24).

Thomson et al. (9) conducted a study to find out the impact of distraction caused by technology on pedestrian crossing behaviors. They did their study in 20 high-risk intersections in Seattle America in three different random time intervals. Pedestrian crossing behaviors of 1,102 people were recorded, results showed that about one third (29.8\%) of pedestrians were involved in distraction when crossing the street. These distractions include listening to music (11.2\%), writing short messages (7.3\%) and mobile phone use (6.2\%). The average crossing time indicated that when writing messages, it took about $18 \%$ more for crossing, which showed that these people were at risk about 3.9 times more than normal people (9).

Alternatively, Neider et al. (8) investigated the effects of mobile phone usage and listening to music amongst the pedestrians. The study was conducted on 36 patients (19 females and 17 males with a mean age of 21.75 years, age range 18 - 30 years) at the University of Illinois in a virtual environment pedestrian crossing. The research results showed that pedestrians who used their cell phone when crossing the street and who listened to music, compared to ordinary people, were less likely to cross the street successfully.

Given the fact that little is known about the impact of mobile phone usage on pedestrians' distraction as mentioned above and due to the scarcity of research on this topic, the present researchers aim to investigate the effects of mobile phone use on the pedestrians' distraction in Iran.

\section{Objectives}

The current research was concerned with aspects of mobile phone use and pedestrian distraction when talking on a mobile device.

\section{Patients and Methods}

\subsection{Methods and Data Collection Procedures}

\subsubsection{Participants}

The present study included 60 (30 males and 30 females) university students from the Islamic Azad University of Gorgan, Iran, who were asked to take part in the mobile phone test. All participants had normal vision or corrected to normal vision (full color vision: 20/20).

In order to prevent participants' awareness from the purpose of the survey, which could possibly affect the results of their consciousness, it was announced to all the participants that this study would only examine the performance of mobile operators on the university campus. The participants took part in the survey after introduction to and signed a consent form. This study was approved by the ethics committees of Golestan University. Written informed consent from all participants involved in the study was obtained. 


\subsection{Study Design and Procedures}

A specific route was selected for the field experiment, within the University of Gorgan campus, Iran. The total length of the route was 500 meters. The survey was carried out during September 2014 when the university was open. Prior to the study, the participants filled out a brief questionnaire regarding their personal characteristics, especially mobile phone usage.

Volunteers participating in the study were divided into two groups. The experimental group received phone calls all the way through while the control group did not receive any phone call. The participants in the experimental group, conversation mode, were asked questions regarding a variety of mobile operators on the way, presented in Table 1, whereas the participants in the control group, not in conversation mode, were announced to continue their path if they had no calls and wait for calls.

Table 1. Sample Conversations Used for Phone Distraction Situation

\begin{tabular}{l}
\hline Sample Conversations \\
\hline Hi, what's your name?.... \\
\hline Hi, my name is... \\
\hline What's your last name?... \\
\hline My last name is ... \\
\hline What do you use your mobile operator?... \\
\hline I use from ... operator. \\
\hline Why did you choose this type of operator? \\
\hline I choose this operator because ... \\
\hline Which mobile operator your friends use? \\
\hline Most of my friends use from... operator. \\
\hline Do you use of your cell phone's internet? \\
\hline Do you ever use the video calling system? \\
\hline How many hours a day do you use a cell phone mean? \\
\hline Do you have information about a third generation mobile operator? \\
\hline Do you have suggestion on improving services for mobile operators? \\
\hline We appreciate your cooperation in this investigation. \\
\hline
\end{tabular}

Before the study, five "out of place" objects had been placed along the route, two at eye level, the safety word and danger sign and three at ground level, cans, polystyrene and a shoe. At the end of the test path, few tables and chairs were placed so that volunteers in both groups could enjoy short entertainment while they were asked to fill out a questionnaire.

Each of the five objects of the study was placed in a four part picture series of other objects. Figure 1 shows that the cans were amongst cups, bottle and crumpled pa- per. Strictly the stop sign was in combination with danger sign, stop sign and pedestrian crossing sign. The safety word was amongst, warning, risk and attention words. The shoe picture was combined with pictures of rope, empty box and tap and polystyrene was combined with images of cement, rebar and brick. In the questionnaire, participants were asked which of these objects were seen along the path.

All the participants responded to five questions at the end of the survey and correct and incorrect answers were written on a separate table for each group. At the end of the study, the researchers explained the purpose of the research and expressed their apologies to the participants who were provided with fictional information.

\section{Results}

The analysis of the data revealed that 20\% (30 correct answers out of 150 questions) of the answers were correct for the participants in the experimental group, while $74 \%$ (111 correct answers out of 150 questions) of the answers were correct for the participants in the control group. Data was analyzed using the SPSS Software version 20. Chisquare method was computed where significance level of the study was set at $95 \%$ with an alpha level less than or equal to 0.05 .

According to Table 2, it is observed that the static value of test is 87.79 and sig $=0.00$, namely $\mathrm{p}<0.05$, which indicates that there are significant differences between the two groups with regards to their responses.

\section{Discussion}

It is documented that there is a direct correlation between the number of cellphone users and injuries. In other words, the more usage of cellphones results in more injuries. Pedestrians' deaths and accidents may occur as a result of using a mobile phone if distracted while crossing the street.

The results of this study show that there is a significant difference between the two pedestrian groups, namely conversation and no-conversation mode (30 correct answers as compared to 111 correct answers out of 150 questions). Result of this study was consistent with previous researches that that pedestrians talking on cellphones took longer to cross the street and paid less attention to traffic (8-22). The results also show that alertness and ability to recall events are significantly reduced while using a mobile phone.

The findings of the present study are in line with previous studies corroborating that mobile phone conversation 


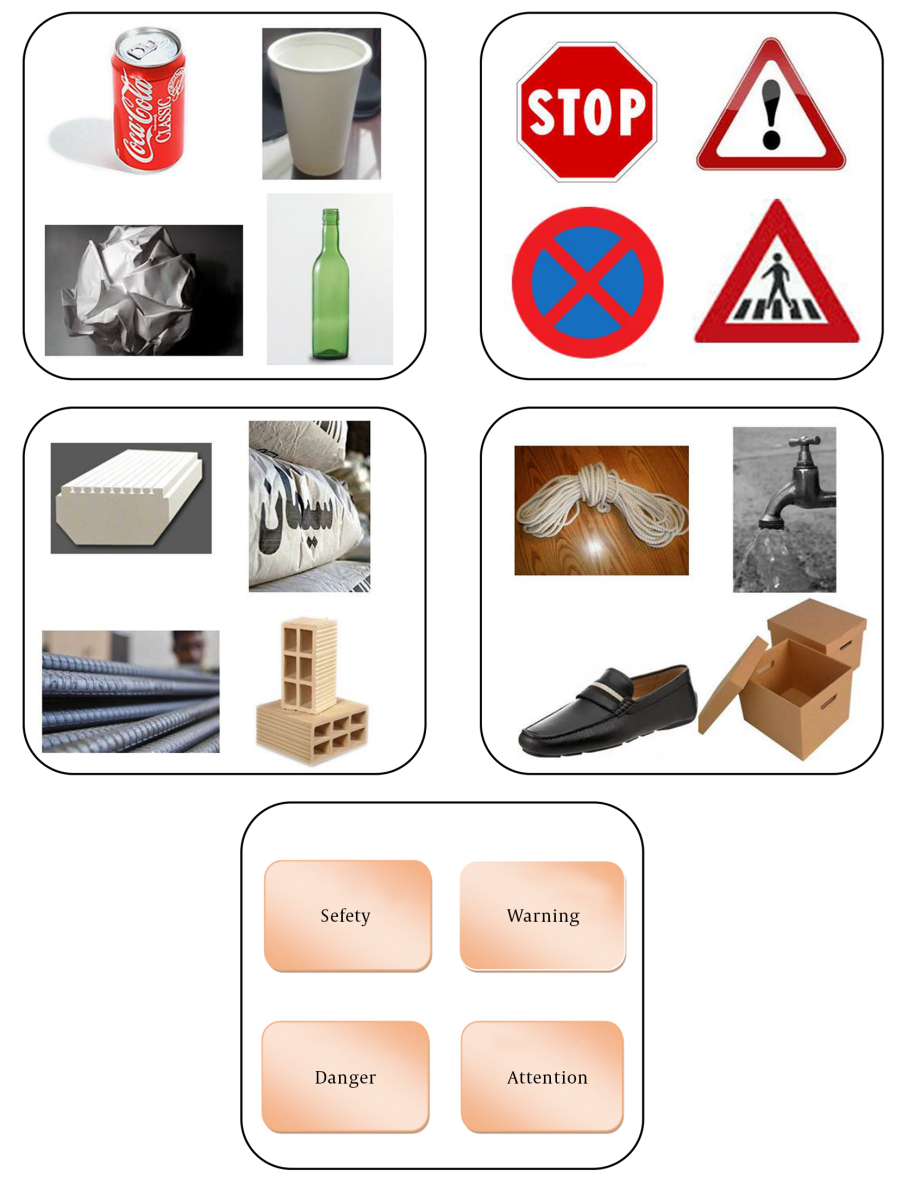

Figure 1. Four Part Picture Series on the Questions at the End of the Survey

Table 2. Chi-Square Test Between Two Groups (Impact of Distraction) ${ }^{\mathrm{a}}$

\begin{tabular}{|c|c|c|c|c|c|c|}
\hline & Value & df & Asymp. Sig. (2-Sided) & Exact Sig. (2-Sided) & Exact Sig. (1-Sided) & Point Probability \\
\hline Pearson Chi-Square & $87.796^{\mathrm{b}}$ & 1 & 0.000 & 0.000 & 0.000 & \\
\hline Continuity Correction $^{c}$ & 85.642 & 1 & 0.000 & & & \\
\hline Likelihood Ratio & 92.770 & 1 & 0.000 & 0.000 & 0.000 & \\
\hline Fisher's Exact Test & & & & 0.000 & 0.000 & \\
\hline Linear-by-Linear Association & $87.503^{\mathrm{d}}$ & 1 & 0.000 & 0.000 & 0.000 & 0.000 \\
\hline $\mathrm{N}$ of Valid Cases & 300 & & & & & \\
\hline
\end{tabular}

${ }^{\mathrm{a}}$ For $2 \mathrm{x} 2$ crosstabulation, exact results are provided instead of Monte Carlo results.

${ }^{\mathrm{b}} 0$ cells $(.0 \%)$ have expected count less than 5 . The minimum expected count is 70.50 .

${ }^{c}$ Computed only for a $2 \times 2$ table.

${ }^{\mathrm{d}}$ The standardized statistic is -9.354 .

might result in pedestrians' distraction and increase the risk of pedestrians' crashes (25-28). Talking on cellphone considerably reduces attention to the unusual surroundings which leads to many accidents.
Given the importance of the matter and a large number of pedestrians who are injured or lose their life every year due to the usage of mobile phones while crossing the street, it is essential that legislation enact strict laws for 
this group of pedestrians. However, if enforcement of law is difficult, people should be made aware of the possible dangers involved. However, legislation alone cannot be enough.

\subsection{Conclusions}

Due to the fact that the use of mobile technology is growing in recent years, it is necessary to spread public awareness and provide a better and safer environment for pedestrians. It is mandatory that individuals should be educated and they should be made aware of the possible dangers involved. For instance, it may be influential to put up information regarding the dangers involved around the areas where pedestrians would approach the intersections and cross walks. Moreover, parents should train their children in different fields. It is necessary to be given adequate training in the field of mobile phone usage and its possible risks as well as teach them its appropriate culture. The children should be taught to look at both sides of the street when crossing the street. They should also be taught to put their cell phones away while walking in the street especially when they are crossing a street, or when they are at the intersections.

\section{Acknowledgments}

The authors thank all the respondents for their time in supporting this research.

\section{Footnotes}

Authors' Contribution: All authors (Seyed Rasoul|Davoodi and Naser Alejalil) participated in the study design, the conception of research questions and the drafting of the paper. Naser Alejalil led the work and wrote the first draft of the paper.

Conflict of Interests: The authors declare that they have no competing interests.

\section{References}

1. MobiThinking . All quality mobile marketing research, mobile web stats, subscribers, ad revenue, usage trends 2011. Available from: http: //mobithinking.com/mobile-marketing-tools/latest-mobile-stats.

2. ITU . ICT Data and Statistics Division Telecommunication Development Bureau International Telecommunication Uni 2013. Available from: www.itu.int.

3. WHO . Pedestrian safety: A road safety manual for decisionmakers and practitioners 2013. Available from: http://www.who.int/ roadsafety/projects/manuals/pedestrian/en/.

4. Ameri M, Karimnia A. Epidemiological characteristics of fatal pedestrian accidents in Iran. Rahvar. 2014;26(1).
5. Bungum TJ, Day C, Henry LJ. The association of distraction and caution displayed by pedestrians at a lighted crosswalk. I Community Health. 2005;30(4):269-79. [PubMed:15989209].

6. Hatfield J, Murphy S. The effects of mobile phone use on pedestrian crossing behaviour at signalized and unsignalized intersections. Accid Anal Prev. 2007;39(1):197-205. doi: 10.1016/j.aap.2006.07.001. [PubMed: 16919588].

7. Nasar J, Hecht P, Wener R. Mobile telephones, distracted attention, and pedestrian safety. Accid Anal Prev. 2008;40(1):69-75. doi: 10.1016/j.aap.2007.04.005. [PubMed: 18215534].

8. Neider MB, McCarley JS, Crowell JA, Kaczmarski H, Kramer AF. Pedestrians, vehicles, and cell phones. Accid Anal Prev. 2010;42(2):589-94. doi: 10.1016/j.aap.2009.10.004. [PubMed: 20159083].

9. Thompson LL, Rivara FP, Ayyagari RC, Ebel BE. Impact of social and technological distraction on pedestrian crossing behaviour: an observational study. Inj Prev. 2013;19(4):232-7. doi: 10.1136/injuryprev2012-040601. [PubMed: 23243104].

10. Sleet DA, Pollack K, Rivara F, Frattaroli S, Peek-Asa C. It wouldn't hurt to walk: promoting pedestrian injury research. Inj Prev. 2010;16(3):211-2. doi: 10.1136/ip.2010.027821. [PubMed: 20570990].

11. Chen X, Zhu Y, Wang G, editors. Evaluating a mobile pedestrian safety application in a virtual urban environment. Proceedings of the 11th ACM SIGGRAPH International Conference on Virtual-Reality Continuum and its Applications in Industry. 2012; ACM; pp. 175-80.

12. Byington KW, Schwebel DC. Effects of mobile Internet use on college student pedestrian injury risk. Accid Anal Prev. 2013;51:78-83. doi: 10.1016/j.aap.2012.11.001. [PubMed: 23201755].

13. Schwebel DC, Stavrinos D, Byington KW, Davis T, O'Neal EE, de Jong D. Distraction and pedestrian safety: how talking on the phone, texting, and listening to music impact crossing the street. Accid Anal Prev. 2012;45:266-71. doi: 10.1016/j.aap.2011.07.011. [PubMed: 22269509].

14. Strayer DL, Drews FA. Profiles in driver distraction: effects of cell phone conversations on younger and older drivers. Hum Factors. 2004;46(4):640-9. [PubMed: 15709326].

15. Johnson MB, Voas RB, Lacey JH, McKnight AS, Lange JE. Living dangerously: driver distraction at high speed. Traffic Inj Prev. 2004;5(1):1-7. [PubMed: 14754669].

16. Matthews R, Legg S, Charlton S. The effect of cell phone type on drivers subjective workload during concurrent driving and conversing. Accid Anal Prev. 2003;35(4):451-7. [PubMed:12729809].

17. Grant AH. Mobile cellular telephony vs. defensive safe driving. Optometry. 2000;71(7):415-7. [PubMed: 15326894].

18. Langer P, Holzner B, Magnet W, Kopp M. Hands-free mobile phone conversation impairs the peripheral visual system to an extent comparable to an alcohol level of 4-5 g $100 \mathrm{ml}$. Hum Psychopharmacol. 2005;20(1):65-6. doi:10.1002/hup.654. [PubMed:15614838].

19. Laberge-Nadeau C, Maag U, Bellavance F, Lapierre SD, Desjardins D, Messier S, et al. Wireless telephones and the risk of road crashes. Accid Anal Prev. 2003;35(5):649-60. [PubMed: 12850065].

20. Cooper PJ, Zheng Y, Richard C, Vavrik J, Heinrichs B, Siegmund G. The impact of hands-free message reception/response on driving task performance. Accid Anal Prev. 2003;35(1):23-35. [PubMed: 12479894].

21. Crundall D, Underwood G, Chapman P. Driving experience and the functional field of view. Perception. 1999;28(9):1075-87. [PubMed: 10694958].

22. Hyman IE, Boss SM, Wise BM, McKenzie KE, Caggiano JM. Did you see the unicycling clown? Inattentional blindness while walking and talking on a cell phone. Appl Cogn Psychol. 2010;24(5):597-607.

23. Stavrinos D, Byington KW, Schwebel DC. Distracted walking: cell phones increase injury risk for college pedestrians. I Safety Res. 2011;42(2):101-7. doi: 10.1016/j.jsr.2011.01.004. [PubMed: 21569892].

24. Nasar JL, Troyer D. Pedestrian injuries due to mobile phone use in public places. Accid Anal Prev. 2013;57:91-5. doi: 10.1016/j.aap.2013.03.021. [PubMed: 23644536].

25. Byrnes JP, Miller DC, Schafer WD. Gender differences in risk taking: A meta-analysis. Psychol Bull. 1999;125(3):367. 
26. Patten CJ, Kircher A, Ostlund J, Nilsson L. Using mobile telephones: cognitive workload and attention resource allocation. Accid Anal Prev. 2004;36(3):341-50. doi: 10.1016/S0001-4575(03)00014-9. [PubMed: 15003578].

27. Strayer DL, Johnston WA. Driven to distraction: dual-Task studies of simulated driving and conversing on a cellular telephone. Psychol Sci. 2001;12(6):462-6. [PubMed: 11760132].

28. Redelmeier DA, Tibshirani RJ. Association between cellular-telephone calls and motor vehicle collisions. NEngl J Med. 1997;336(7):453-8. doi: 10.1056/NEJM199702133360701. [PubMed: 9017937]. 